\title{
LAS ESCUELAS NORMALES EN TIEMPOS DE JUAN VICENTE GÓMEZ
}

\author{
AS ESCOLAS NORMAIS NO TEMPO DE JUAN VICENTE \\ GÓMEZ
}

\section{THE NORMAL SCHOOLS IN THE TIMES OF JUAN VICENTE GÓMEZ}

\author{
Luis Peñalver Bermúdez² \\ Universidad Pedagógica Experimental Libertador - UPEL
}

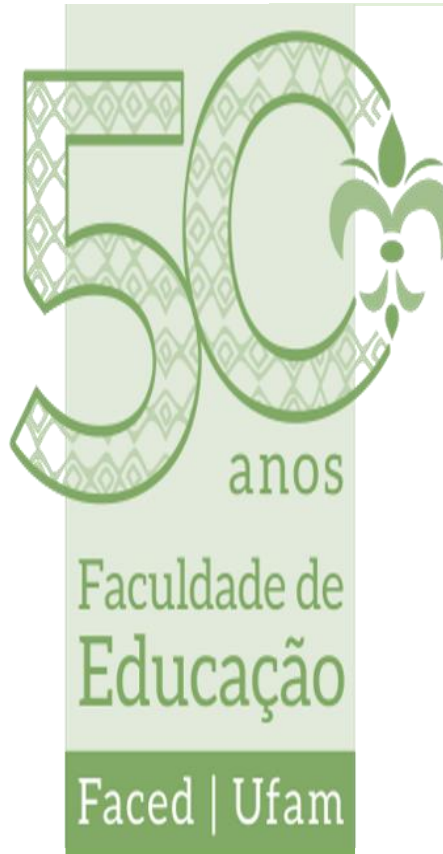

\section{Resumen}

El tema de la formación docente constituye una prioridad tanto para el Estado venezolano, como para las universidades de las cuales egresan profesionales que se dedicarán al trabajo pedagógico. En este contexto, un aspecto no atendido suficientemente es el referido a la historia de la formación docente en Venezuela, particularmente lo que se refiere al origen, desarrollo, decadencia y extinción de las escuelas normales. Desde las posibilidades metodológicas de la investigación histórica y la crítica documental, podrán ofrecerse nuevas perspectivas y temas de investigación, con una base de fuentes que tiene un recorrido desde mediados del siglo XIX, hasta la década de los '80 en siglo XX. Contar con la oportunidad de tener a la mano la documentación y las fuentes para el estudio de la formación docente en Venezuela, particularmente en lo que a las Escuelas Normales se refiere, es intentar explicar parte de lo que hoy se tiene como proyecto formativo nacional.

Palabras clave: Escuelas Normales; Juan Vicente Gómez; Formación Docente; Venezuela.

\footnotetext{
${ }^{1}$ El presente texto constituye la primera entrega del Proyecto: La Historia de la Formación Docente en Venezuela, que recibió financiamiento del Vicerrectorado de Investigación y Postgrado de la Universidad Pedagógica Experimental Libertador (Venezuela).

2 Sus estudios de pregrado los realizó en el Instituto Universitario Pedagógico Experimental de Maturín, la maestria en la Universidad Gran Mariscal de Ayacucho y el doctorado en la Universidad Pedagógica Experimental Libertador. Está adscrito a Centro de Investigaciones "Dr. J. R. Zambrano, dónde trabaja con las líneas de a) Historia de la Educación y la Formación Docente y b) Historia Local y Regional. Actualmente es investigador y asesor curricular en el Centro Nacional de Historia. ORCID: https://orcid.org/0000-0002-1966-1883. E-mail: luisrafaelpenalver@gmail.com.
} 


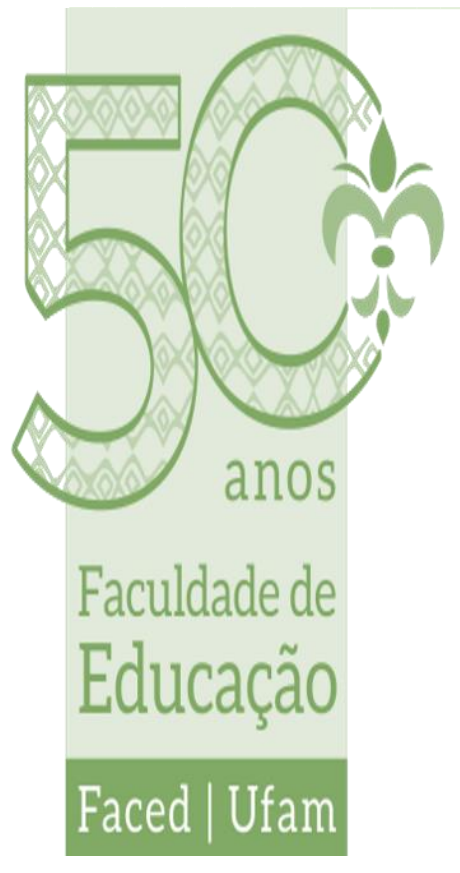

\section{Resumo}

A questão da formação de professores constitui uma prioridade tanto para - Estado venezuelano quanto para as universidades nas quais se formam profissionais que se dedicarão ao trabalho pedagógico. Nesse contexto, um aspecto não suficientemente abordado é o referente à história da formação de professores na Venezuela, particularmente no que diz respeito à origem, ao desenvolvimento, ao declínio e extinção de escolas normais. A partir das possibilidades metodológicas da pesquisa histórica e da crítica documental, novas perspectivas e tópicos de pesquisa podem ser oferecidos, com uma base de fontes que possui uma trajetória de meados do século XIX até a década de 1980, no século XX. Ter a oportunidade de ter em mãos a documentação e as fontes para o estudo da formação de professores na Venezuela, particularmente no que se refere às Escolas Normais, é tentar explicar parte do que hoje é um projeto de treinamento nacional.

Palavras-Chave: Escolas Normais; Juan Vicente Gómez; Formação de Professor; Venezuela.

\section{Abstract}

The issue of teacher training constitutes a priority, both for the Venezuelan State, and for the universities from which professionals graduate, who will dedicate themselves to the pedagogical work. In this context, a not sufficiently addressed aspect is that referring to the history of teacher education (teaching education) in Venezuela, particularly, as regards the origin, development, decline and extinction of normal schools. From the methodological possibilities of historical research and documentary criticism, new perspectives and research topics can be offered, with a source base that has a trajectory from the mid-nineteenth century to the 1980 s in the twentieth century. Having the opportunity to have on hand the documentation and sources for the study of teacher training in Venezuela, particularly in what refers to the Normal Schools, this research tries to explain part of what is now a national training project.

Key words: Normal Schools; Juan Vicente Gómez; Teacher Training; Venezuela.

\section{INTRODUCCIÓN}

\section{Antecedentes de investigación}

A lo largo historia de la educación venezolana, se ha venido conformando un sistema de pensamiento que sintetiza, en distintos momentos, formas de educar, concepciones de la educación y de las instituciones escolares, visión del magisterio y de su formación, visión del estudiante, papel de la sociedad y del Estado, sistemas de valores, diseños curriculares, textos escolares, entre otros. Ese 


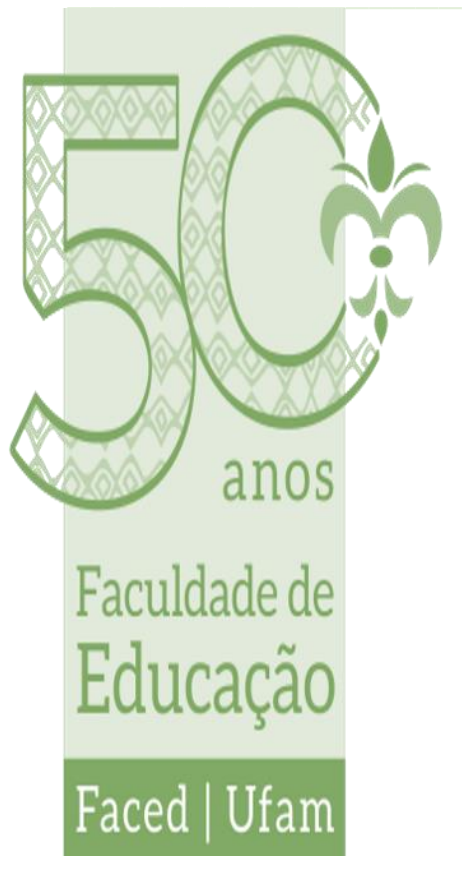

conjunto, bien pudiera denominarse pensamiento pedagógico, que, como se aprecia, tiene un sentido aglutinador y las fracturas, influencias filosóficas, políticas e ideológicas, fundamentalmente, lo determinan en diversos momentos de la vida socio-política del país. Pudiera señalarse, hipotéticamente, que en cada época o coyuntura, según las determinaciones, se configura un pensamiento pedagógico de peculiares características.

Desde esta perspectiva, parte del esfuerzo pendiente, como maestras y maestros en un momento tan importante para Venezuela, es inquietarse por la propia historia de la educación, por las propias ideas pedagógicas, sin olvidar los contextos necesarios fuera de nuestras fronteras, donde ocurren acontecimientos vinculantes con la realidad educativa y pedagógica.

Venezuela cuenta con esfuerzos extraordinarios que permiten apreciar la educación y el pensamiento pedagógico, desde una perspectiva histórica. Autores como Rafael Fernández Heres (1981) y Guillermo Luque (2008), por ejemplo, son referencia fundamental en los estudios de estos campos. $\mathrm{Y}$ esto es parte sensible, pedagógicamente hablando, de la cantera de ideas que están por estudiarse o que se están estudiando, sobre la formación docente y, en particular, de las instituciones que han tenido y tienen tamaña responsabilidad.

En el caso que ocupa el presente artículo, sobre las escuelas normales de Venezuela, hay destacados aportes desde los que se puede apreciar cómo han ido variando los temas de trabajo y los propósitos. Persiste la visión histórica con apoyo de fuentes documentales de la época, medio fundamental para garantizar el origen del dato, su descripción y tratamiento. Tales aportes siguen a continuación.

Con el título: "Gomecismo y educación: reforma, contrarreforma y nuevas reformas. 1900- 1930", Luque (2001) se dedica a destacar tres personajes que influyeron de manera notable en la educación venezolana, durante el período 1899-1935 ellos fueron: José Gil Fortoul (historiador), Felipe Guevara Rojas (médico) 
y Rubén González (jurista). Refiere Luque, que les correspondió un destacado "desempeñó en circunstancias políticas muy particulares que, en parte, explican su actuación" (Luque, 2001, párr. 1). Igual que en casos posteriores, el autor da sitial destacado al tema de las escuelas normales. Mientras que Fourtoul fue partidario, por un lado, de convertir la docencia en una profesión donde los referentes formativos fueran similares a los de los médicos e ingenieros $y$, por el otro, de promover reformas en el ámbito de las escuelas normales; Guevara Rojas propició los concursos para los cargos de maestros y profesores y defendió la libertad absoluta para la participación en el desarrollo de la educación; y González mantuvo el principio, aun se mantiene, que la instrucción pública debe estar sometida al control del Estado.

Pinto Iglesias y García García (2002), llevaron a cabo una investigación titulada: "La formación de formadores en Venezuela: la formación de maestros", dedicada a profundizar sobre el proceso de formación pedagógica, desde los inicios republicanos, hasta 1935. Centraron el discurso en exponer los criterios de los responsables de la política educativa en la importancia de reconocer la necesidad de formación del magisterio y en la creación de las escuelas normales.

"Las reformas educativas de Felipe Guevara Rojas (19141916)", es el título que define Olivar (2014), para desarrollar un artículo dedicado a Felipe Guevara Rojas, quien se desempeñó, durante los primeros años del gobierno del general Juan Vicente Gómez, primero como rector de la Universidad Central de Venezuela y luego como Ministro de Instrucción Pública. Entre sus contribuciones está la reforma educativa que impulsó en las educaciones primarias, secundarias y universitarias. Para el caso de las escuelas normales, Olivar expone las gestiones de Guevara al respecto, incluyendo adquisición de materiales, contratación de normalistas extranjeros, formación de maestros y la figura del internado.

Para 2014, en un artículo denominado: "Una mirada a las políticas educativas del Estado venezolano desde el llustre 


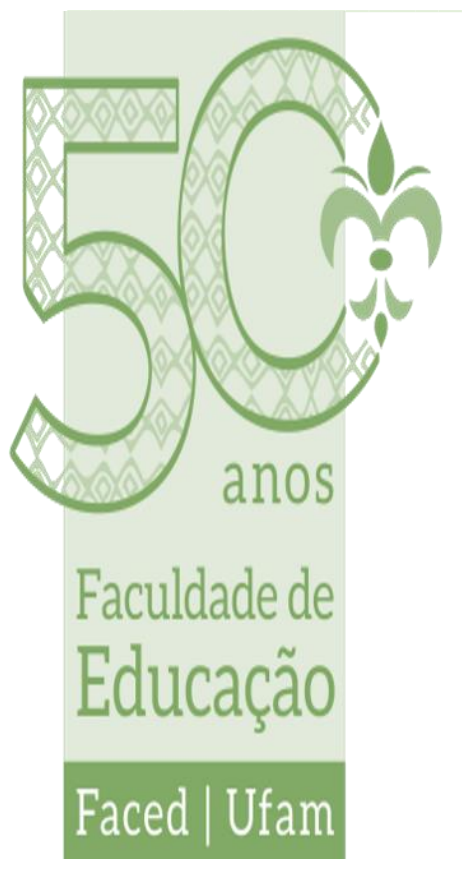

americano (1870) al Benemérito (1935)", Abreu Suárez se dedica a reflexionar en torno a las políticas educativas venezolanas, en el período 1870-1935, que cubre los gobiernos de Antonio Guzmán Blanco, Andueza Palacios, Joaquín Crespo, Cipriano Castro y Juan Vicente Gómez. Aun cuando son analizadas algunas reformas educativas de la época, hay una destacada e importante mención a las escuelas normales, incluyendo la larga etapa que corresponde a Juan Vicente Gómez.

Vargas Ponce (2020), realizó una investigación con fuentes documentales, titulada: "Las escuelas normales y la formación docente en Venezuela, 1900-1935", que los períodos de gobierno de Cipriano Castro y de Juan Vicente Gómez. El autor da cuenta de los eventos críticos relacionados con la evolución de las escuelas normales, destacando, entre otros, los juicios y propuestas de Trino Batista, José Gil Fortoul, Rafael González Rincones y Rubén González Cárdenas; la importancia -por su contenido- de determinados cuerpos jurídicos y las creaciones de la Escuela Normal para Hombres y la Escuela Normal de Mujeres.

\section{J. V. GÓMEZ EN EL PODER, 1908-1935}

El gobierno de Cipriano Castro (1899-1908), se desarrolló bajo los efectos de una aguda crisis económica que se había iniciado en 1897 y se mantuvo hasta un año después de su salida del poder. Junto a esa situación, se hicieron presentes: los enfrentamientos fratricidas como la Revolución Libertadora y la presión internacional por los reclamos, principalmente, de Alemania, Inglaterra e Italia, entre otros acontecimientos de esencial importancia.

El Jefe Supremo de la República (una de las titulaciones oficiales), con una Constitución modificada a sus intereses, sin adelantar cambios profundos en la estructura económica y social de Venezuela y manteniendo vivas las ambiciones del caudillismo, recibió el movimiento traidor de su primer vicepresidente, apoyado éste por los sectores dominantes y las potencias externas; así, Juan 


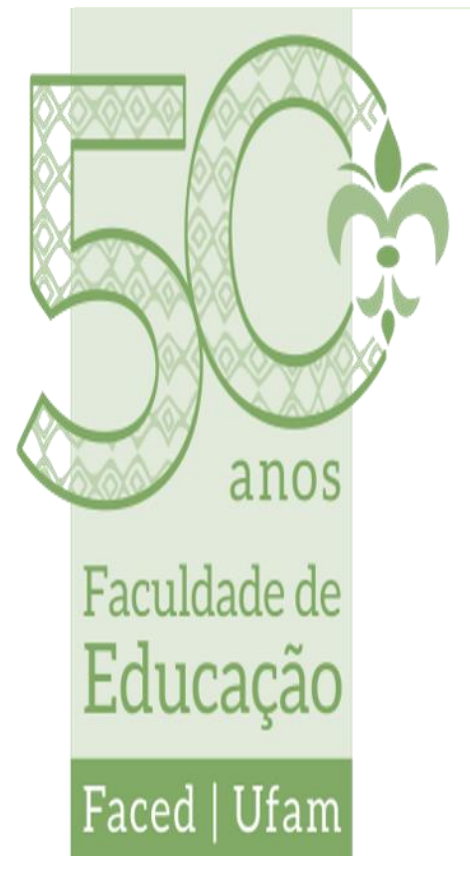

Vicente Gómez toma la presidencia del país. Ese golpe de Estado, con el resguardo complaciente tanto del gobierno como de las compañías norteamericanas, justificó un régimen dictatorial por veintisiete años.

Al asumir el poder, el 20 de diciembre de 1908, Juan Vicente Gómez se dirige al pueblo venezolano en los siguientes términos:

Compatriotas! Ya sabéis que vine á desempeñar el Poder Ejecutivo Nacional. La ley me llamó al puesto, y desde el primer momento me di á conciliar las aspiraciones populares con mis deberes públicos, procurando establecer un régimen de garantías en consonancia con nuestras instituciones. He querido y quiero para cada venezolano la efectividad de sus derechos, sin ser esta aspiración concesión ó merced, sino únicamente la imposición de la Ley.

Pero mis mejores intenciones y deseos han encontrado, desgraciadamente, un inexplicable obstáculo en algunos pocos ciudadanos que, llamándose íntimos amigos del ciudadano General Cipriano Castro, no sólo se han atravesado en el camino de mis deberes legales, sino que han bajado al antro de la conjuración y fraguado contra mi vida el plan diabólico que hice abortar en la mañana de ayer, enfrentándome á los mismos conjurados y reduciéndolos á prisión.

Al proceder así, conciudadanos, no solo he defendido mi vida, sino algo que vale más que mi existencia personal, porque he procurado salvar el decoro y el prestigio de la Magistratura que desempeño y que aspiro convertir en manantial de bienes para todos los venezolanos (GÓMEZ, 1909, pp. 6-7)

En el resto del Manifiesto, Gómez notifica haber constituido un nuevo Gabinete, promete paz y armonía, reclama apoyo moral y material, para terminar recordando "que la fórmula de la República es la que se encierra entre la modestia y el ardiente patriotismo". ( $p$. 7) Así comenzó un largo tiempo de 27 años, marcando la vida del pueblo venezolano, que estando en los inicios del siglo veinte (1908), seguía desenvolviéndose con estructuras y pensamientos propios de la mentalidad caudillista decimonónica. El siglo diecinueve venezolano se montó en lomos de la centuria siguiente y remontó un poco más allá de la segunda década. 


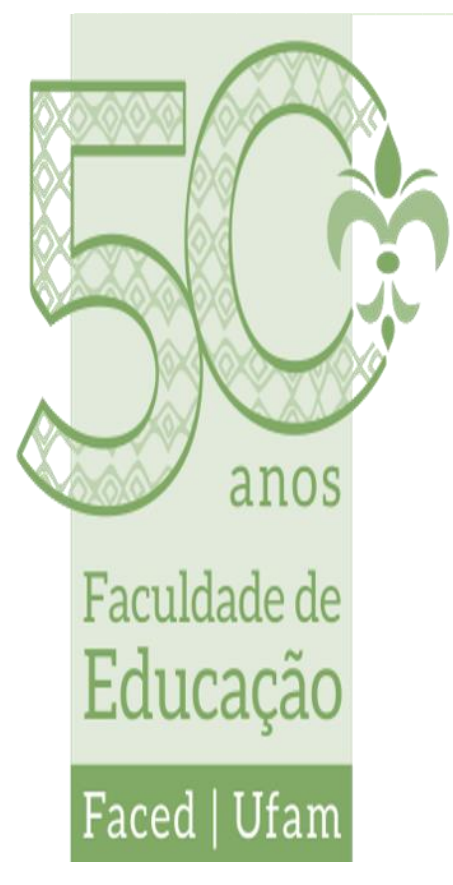

Si pudieran, que comentarían Pedro Cornelio y Hermenegilda de su vástago Juan Vicente, quien desde la Hacienda La Mulera (estado Táchira) y al lado de Cipriano, lograron abrirse paso, cual ejército triunfante, hasta la codiciada ciudad donde aun mora el poder central: Caracas, asumiendo Castro la presidencia republicana. Más tarde, ante la separación involuntaria de la silla de gobierno, Juan Vicente se posesionó, hasta su muerte, de la presidencia. Con una existencia de 78 años, veintisiete habían sido de ejercicio político típicamente caudillista-dictatorial.

Durante el gomecismo (1908-1935) la continuidad se mantuvo con una ecuación política perversa que combinaba: represión, encarcelamiento y expulsión de adversarios. El "ferviente" afán constitucionalista de Juan Vicente Gómez, lo demostró en siete oportunidades modificando la constitución, la decidida oposición al gobierno dictatorial, la utilización de las concepciones positivistas para justificar y defender el régimen, el incremento de las inversiones extranjeras en el ámbito petrolero, el aumento de los ingresos fiscales, los cambios en la estructura social del país, el fortalecimiento del latifundismo, entre otros, pudieran presentarse como aspectos relevantes de la vida venezolana en tiempos de Gómez.

Personalmente, monopolizó el juego, la navegación fluvial y costanera, los ingenios de azúcar y haciendas de cacao y café, más las pequeñas industrias de jabón, cigarrillos, velas, vidrio, aceite, hotelería, etc.

Su poder se apoyaba en el creciente poderío militar que había modernizado con creces: reorganizó la Escuela Militar de Caracas, trajo instructores militares extranjeros, actualizó el armamento, creó la Escuela de Aviación Militar, promulgó una Ley de Servicio Militar Obligatorio, introdujo los primeros automóviles y adelantó la llamada "política de carreteras" para facilitar el traslado del ejército hasta zonas del interior del país.

La educación, desde los tiempos de Castro ya mostraba señales desalentadoras; en parte, por los enfrentamientos político- 
militares que eran muy frecuentes en un país de corte caudillista. En 1902, el Ministro Tomás Garbiras, indicaba que los furores de guerra civil, que se habían heredado desde 1835, afectaban todos los ramos de la administración pública.

En 1911, siendo José Gil Fortoul Ministro de Instrucción Pública, nuevas y frescas posibilidades comienzan a perfilarse en la educación venezolana, donde es fundamental el apoyo de especialistas como el destacado maestro Guillermo Todd, quien tenía un caudal de experiencias, adquiridas en el país y las había potenciado gracias a un viaje de estudios que había realizado a los Estados Unidos de Norteamérica; esfuerzo que continuó durante la gestión de Guevara Rojas. El maestro Todd definió diversas iniciativas para el ramo educativo nacional y puso especial énfasis en la formación del magisterio, pues veía en la Escuela Normal la posibilidad de ser centro de excelencia, donde debía morar lo que refería como espíritu pedagógico. (Ver FERNÁNDEZ HERES, 2005).

Luego de la gestión ministerial de Gil Fortoul (1911-1913), el nuevo responsable de la educación nacional sería Felipe Guevara Rojas, quien siguió a grandes rasgos la política educativa que venía desarrollándose. En el caso del magisterio, son notables las decisiones relacionadas con los concursos para la provisión de cargos. Un salto cualitativo de grandes dimensiones ocurrió con la creación de la Escuela Normal de Hombres, que inició sus actividades en 1913. Para arrancar tal acontecimiento históricopedagógico, se contrató al profesor Ernest Cachín, de Suiza, quien tendría a su cargo la Dirección de la Escuela Normal. Mientras tanto, en espera de su llegada, tal responsabilidad quedaba en manos de José Ramón Camejo, quien venía ejerciendo como Subdirector.

En 1914, aun con el fresco inicio de la Escuela Normal y la salida abrupta de Ernest Cachín y sus experiencias pedagógicas europeas, el gobierno de la República de Chile dispuso varias becas para seguir estudios normalistas en la ciudad de Santiago. Un grupo integrado por Félix Armando Núñez, Rafael Alvarado, Alberto Escobar Lara, Alirio Arreaza y Luís Gotbert, constituyó la avanzada 


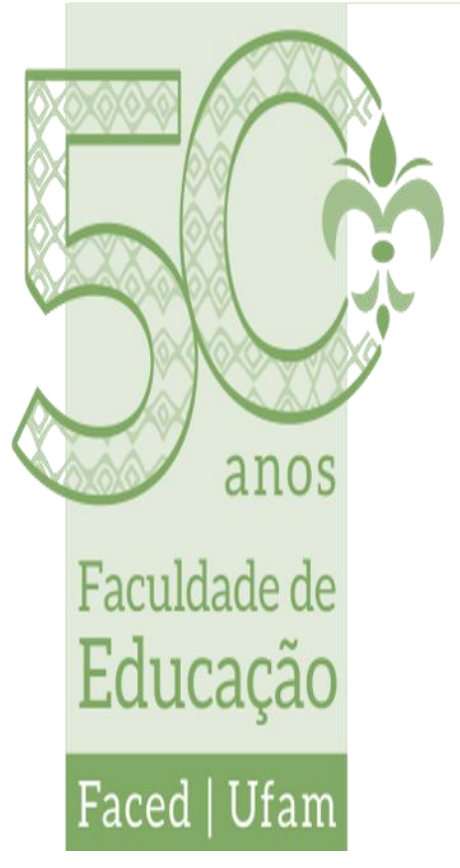

pedagógica que luego dejaría huella tanto en Venezuela como en Chile.

La muerte repentina de Guevara Rojas, motivó el nombramiento de Carlos Aristimuño Coll, al que luego sucedieron: Rafael González Rincones, José Ladislao Andara y Rubén González, quien estuvo en el cargo desde 1922 hasta 1929. González retoma el aliento transformador, haciendo empeño en la legislación de la instrucción pública, devolviendo al Estado el control del proceso educativo. Merecen destacarse su llamado a implementar un plan de emergencia que permitiera atender la formación del magisterio, la revisión del plan de estudios, los intercambios con países como Argentina y la revisión de las prácticas pedagógicas.

De manera general, la gestión educativa gomecista cerraba en 1935 con apenas 1372 escuelas primarias, de las cuales 1175 continuaban siendo atendidas por un solo maestro; de 698288 niños en edad escolar, se matriculan 137000 (ver GOVEA DE CARPIO, 1990, p. 57). En cuanto a las escuelas normales, es a partir de 1928 cuando ocurre un ascenso en la matrícula, que en versión de Portillo y Bustamante (1999), fue "producto del aumento de sueldo que hizo más atractiva la profesión docente. Además, una nueva generación de jóvenes deseosos de una nueva concepción política buscan entrar en la docencia" (p. 34). A manera de síntesis, señala Govea de Carpio:

Desde sus orígenes, en 1876, hasta bien avanzado el siglo XX, la formación docente en Venezuela vivió lo que se podría considerar como un largo periodo de gestación. Durante más de medio siglo, con mayor o menor empeño según la época, se luchó sin mucho éxito, por establecer en el país la carrera del magisterio. El venezolano se resistió durante mucho tiempo a aceptar que la docencia era una profesión para la cual se necesitaba estudiar. La mayor parte de los maestros en servicio habían optado por esta carrera en forma accidental, o como una salida salvadora, cuando no encontraban otra cosa que hacer. (GOVEA DE CARPIO, 1990, p. 69). 


\section{EDUCACIÓN NORMALISTA}

Durante el tiempo de estructuración, reestructuración y transformación del sistema educativo nacional, se han mantenido, con unas $u$ otras identificaciones, instituciones que en el marco de las políticas públicas del sector, son recurrentes. Durante la gestión de Juan Vicente Gómez, se establecieron dos tipos de escuelas normales: las escuelas normales primarias y las escuelas normales superiores. Mientras que en las primeras egresaban maestros de educación primaria, en las segundas eran formados profesores para enseñanza secundaria. "Para ser admitido como alumno del primer año se requiere poseer el Certificado Oficial de Suficiencia en la Instrucción Primaria Completa, tener quince años cumplidos y no más de veinticinco, gozar de salud y buena constitución física..." (MINISTERIO DE INSTRUCCIÓN PÚBLICA, 1917, p. 153)

Durante la época de Juan Vicente Gómez, las escuelas normales constituyeron un referente particular en el ámbito de las políticas públicas, no solo por la importancia que ellas tenían como instituciones para la formación de maestras y de maestros, sino porque también formaron parte del debate propio de la época, donde estaban involucradas las políticas del Estado, sobre todo en instrucciones, reglamentos, códigos y leyes; las exposiciones de los ministros del ramo, presentadas en las memorias ante el congreso de la república; las opiniones de la intelectualidad de la época, productos de las diferencias políticas con el gomecismo; las ideas de la iglesia católica, que en más de una oportunidad sintió que se lesionaban sus principios y los pronunciamientos del gremio pedagógico, agrupado -en 1932- en la Sociedad Venezolana de Maestros de Instrucción Primaria -bajo el liderazgo, entre otros, de Luis Padrino y Luis Beltrán Prieto Figueroa-, luego transformada en la Federación Venezolana de Maestros, aun con vida institucional y política. En sus inicios, la SVM tuvo como fuente de inspiración a la escuela nueva o escuela activa, 


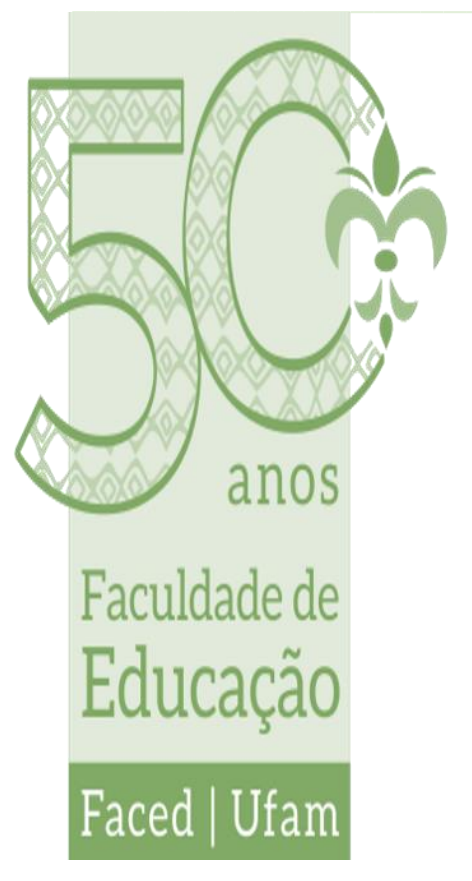

Las Memorias que el Ministro de Instrucción Pública correspondiente presentaba al Congreso de los Estados Unidos de Venezuela, entro otros aspectos, eran la expresión de las políticas públicas, en particular de lo que a escuelas normales se refiere. Presentar ese balance, permitirá dar cuenta de parte del pensamiento de la época y de las decisiones y acciones que se realizaban en consecuencia. De las Memorias, es necesario aclarar, se usaron como fuentes para el presente estudio, exclusivamente las exposiciones o introducciones con información relevante sobre las escuelas normales. Ello explica los saltos en la secuencia cronológica. Durante el gobierno de Gómez, ostentaron el cargo de Ministro de Instrucción Pública, sucesivamente, los ciudadanos: Samuel Darío Maldonado, Trino Baptista, José Gil Fortoul, Felipe Guevara Rojas, R. González Rincones, José Ladislao Andara, Rubén González, Samuel Niño y Rafael González Rincones.

En la Exposición presentada por Rafael González Rincones (MINISTERIO DE INSTRUCCIÓN PÚBLICA, 1918), correspondiente a 1917, específicamente en lo que se refiere al subtítulo de Educación Normalista, el Ministerio declara su intención de evaluar las Escuelas Normales Primarias, esperando que rindan lo que se espera de ellas.

Un problema de origen, por así decirlo, es referido a la insuficiente formación de quienes aspiran obtener títulos de magisterio. Se proponía, entre otros asuntos, un curso de perfeccionamiento con duración de tres años, donde se estudiaría francés, dibujo, gimnasia, música, junto con las asignaturas correspondientes al plan de instrucción primaria y luego un año más, para profundizar estudios de pedagogía, metodología, psicología pedagógica e historia de la educación. Con el tiempo, unidades curriculares como francés, dibujo, música e historia de la educación, fueron presa de concepciones curriculares, donde ya no eran consideradas para la formación magisterial; hasta el presente. 
Una idea innovadora de González Rincones, era la creación de otro internado anexo al existente en las escuelas normales, para iniciarse desde la primaria la formación normalista y, con un Certificado de Instrucción Primaria Elemental, los niños y niñas mayores de 10 años, cursarían quinto y sexto grados en las Escuelas de Aplicación que funcionaban en las escuelas normales, buscando con ello, quizás, despertar la vocación pedagógica desde los estudios en la escuela primaria. Otro planteamiento por atender en la organización de las normales era que la denominada práctica debía comenzar, bajo la vigilancia estricta del maestro o de la maestra, en el segundo año de estudios, siendo este un aspecto recurrente en las distintas administraciones.

En una concepción que involucraba: enseñanza integral, conocimientos positivos, ciencias naturales, ejercicio físico, sano trabajo y gimnasia del espíritu, para la fecha de la Memoria se dictó un decreto donde quedaba establecido, para las escuelas normales primarias, la clase de agricultura práctica, quedando bajo responsabilidad de Henry Pittier, especialista en agricultura tropical, decisión que no solo iba en acuerdo con la visión productiva de la época, aun bajo influencia del pensamiento agropecuario heredado del siglo XIX, sino que era expresión de un dato esencial: el estudiante del magisterio también tendría que estar vinculado a la producción de bienes de consumo.

Durante el año de la cuenta, se llevaron a cabo tres concursos para el otorgamiento de becas de los internados de las escuelas normales primarias. Los dos primeros llamados fueron para mujeres y hombres, y el último fue solo para hombres, donde el resultado favorable fue el siguiente: seis de Caracas, dos de Barcelona, uno de Ciudad Bolívar, uno de Coro y dos de San Felipe, quienes pasaron a formar parte de los internos en la Escuela Normal Primaria de Hombres. Expresa González Rincones que también se realizó el debido concurso para la provisión de veinte becas en el internado de la Escuela Normal Primaria de Mujeres, pero los detalles los expone la Memoria siguiente de 1919; en esa 


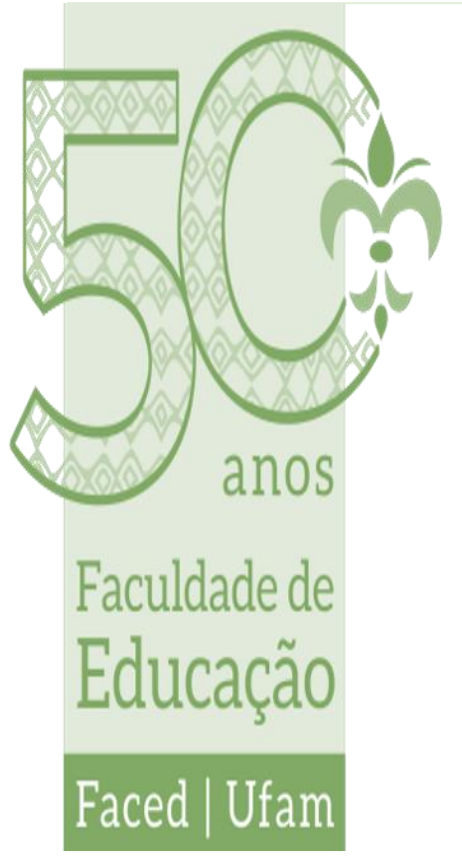

oportunidad, resultaron favorecidas treinta y tres aspirantes: veinte de Caracas, una de Maturín, cuatro de San Cristóbal, una de Barquisimeto, cinco de Barcelona, una de Coro y una de San Felipe. Esta situación deja al interior con una participación exigua en la formación del magisterio, lo que determinó, a lo largo del período gomecista, la presencia mayoritaria de escuelas de un solo maestro o escuelas integradas.

Luego de notificar el otorgamiento de trece títulos de Maestro de Instrucción Primaria, cumplidos los requisitos establecidos en la Ley de Certificados y Títulos Oficiales, González Rincones cierra las referencias de la Instrucción Normalista, en los siguientes términos:

Abrigo la esperanza de que cada día será más próspera la marcha de las Escuelas Normales, a favor de la organización práctica que en ellas ha de establecerse, para que resulten eficaces las patrióticas gestiones que el Ejecutivo Federal hace constantemente, con el objeto de que ellas cumplan a cabalidad la función que les concierne: formar maestros consientes de su deber y responsabilidad, adiestrar obreros legítimos para el próspero porvenir de la patria y la cultura. (MINISTERIO DE INSTRUCCIÓN PÚBLICA, 1918, p. XXIX).

Es notoria en González Rincones la perspectiva de una formación del magisterio vinculada al criterio de responsabilidad y al futuro de la nación y la cultura, generando así una especie de visión del sujeto pedagógico perfilado desde el Ejecutivo Federal.

1918

En esta oportunidad, el Ministro González Rincones (en MINISTERIO DE INSTRUCCIÓN PÚBLICA, 1919), en cuanto a los Institutos de Instrucción Normalista, expresa que no tiene nada que agregar a lo que había dicho en el año anterior, en relación con su estado y funcionamiento. Persiste en lo que él denomina "complementar el sentido práctico" y, en esa dirección, la maestra Antolina González Rincones recibe autorización para dar una clase semanal de corte y confección de vestidos, en el Curso de Trabajos Manuales que se ofrecía en la Escuela Normal Primaria de Mujeres; 
también se autoriza a la maestra Carmen Columba lbarra Delfino, para ofrecer clases de religión a los alumnos cuyos padres así lo solicitaran.

Dos aspectos resaltan acá. El primero, donde la concepción de la formación de las mujeres, aun en el ámbito magisterial, seguía conectada con las tesis de "oficios propios de su sexo", "sexo débil", que correspondían a "los valores y creencias que se habían tejido en torno a la función social de la mujer,..." (Banko en MARTíNEZ VÁSQUEZ, 2005, p. 21); sin embargo, personajes como José Gil Fortoul eran partícipes de revisar los valores instalados al respecto. El segundo, que la presencia de la religión constituía un componente optativo, rompiendo con buena parte de la concepción decimonónica, donde la religión y los postulados de la iglesia se integraban a los planes de enseñanza.

Otro punto de interés en esta gestión, se refiere a lo que hoy día se ha denominado feminización del magisterio. En el inicio del mes de mayo de 1918, se notificó la apertura del concurso para 25 becas en el Internado de la Escuela Normal Primaria de Hombres y, aun cuando se dio un lapso de inscripción de cien días, hubo que prorrogar la convocatoria hasta enero del año siguiente, pero la presentación de aspirantes fue mínima. En un intento de explicación, González Rincones expone lo siguiente: "El magisterio entre nosotros, por causas bien conocidas, atrae las aspiraciones de la mujer, pero no así las del hombre, quien se ve solicitado por otros oficios o profesiones más lucrativas o más de su gusto, con la natural excepción de aquellos que sienten una vocación decidida". (MINISTERIO DE INSTRUCCIÓN PÚBLICA, 1919, p. XXXIX). Un concepto tan sinuoso como la vocación, seguía presente en buena parte del pensamiento de la época.

Al final, para no perder las becas ofrecidas para la Escuela Normal Primaria de Hombres, se decidió utilizarlas para otras instituciones como el Liceo de Caracas y las Escuelas de Comercio y de Artes y Oficios para Hombres. 


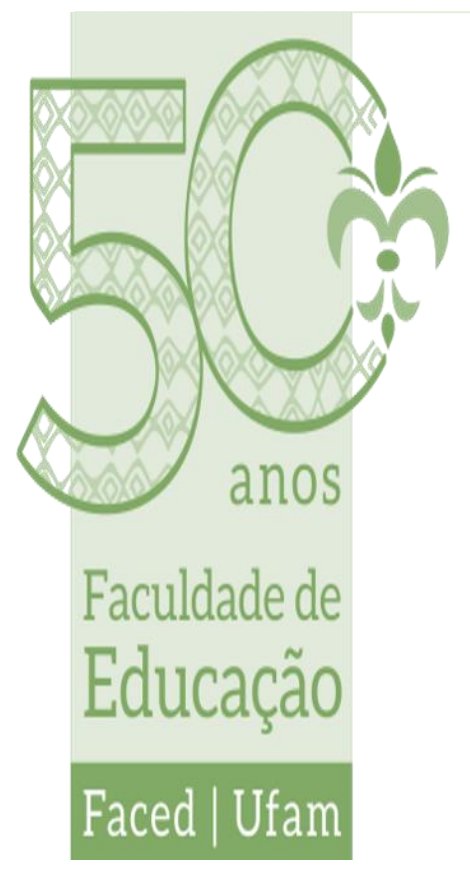

No deja de expresar el Ministro González Rincones, que aun en medio de una crisis mundial, el gobierno del General Gómez había centrado su energía en el patriótico esfuerzo de la prosperidad del país en sus diversas manifestaciones:

Día por día, el Despacho se ocupa en mejorar los elementos de las Escuelas, proveyendo las más necesitadas de lo indispensable, como son, los bancos, pizarrones, mapas, ábacos, cuadros, murales, etc., y solo se espera la oportunidad favorable para acrecentar en debida forma el movimiento progresista. (MINISTERIO DE INSTRUCCIÓN PÚBLICA, 1919, p. XI)

1920

En esta Exposición referida a la Instrucción Normalista, el Ministro González Rincones mantiene la preocupación por "la falta de personas competentes para desempeñar cumplidamente la misión del Maestro". (FERNÁNDEZ HERES, 1981, p. 869) Sus ideas en ese sentido, toman la siguiente dirección: adoptar un plan de emergencia para atender la problemática que comprenda un sistema para la formación de maestros y maestras en las mismas localidades donde desempeñarán su profesión, atendiendo, por supuesto, los requerimientos sobre personal docente, infraestructura y material de enseñanza; no obstante, un asunto que no ayuda mucho esa posibilidad, es la forma de realización de los concursos, pues cuando no quedan desiertos, es que quienes aspiran son pocos y ello afecta sobre todo a las escuelas que están más allá de la ciudad de Caracas. Fue realmente revolucionario pensar en una formación del magisterio que se llevara a cabo en los mismos lugares donde los maestros desempeñaran su responsabilidad, lo que implicaría, figuradamente, que a la escuela normal le correspondería ir a la escuela primaria. Quizás, ello podía haber incrementado el número de aspirantes al magisterio y así cubrir las vacantes del interior del país.

En la perspectiva anterior, el proyecto de González Rincones implicaría incrementar el número de becas por entidad federal, distribuidas en cuatro para varones y cuatro para niñas y 
correspondería a los gobiernos de los estados y de las municipalidades, apoyar al Ejecutivo Federal, costeando la manutención de cuatro estudiantes, dos varones y dos niñas, lo que para las arcas regionales representaría una erogación de 320 Bs. mensuales.

Otra preocupación del Despacho, estuvo referida al problema de infraestructura; así las cosas, "el gobierno ha arrendado un lujoso edificio para la Escuela Normal de Mujeres y no ha mucho dispuso la compra de otro para instalar en él la Escuela Normal de Hombres" (FERNÁNDEZ HERES, 1981, p. 869), situado en la Avenida El Paraíso. Como peculiaridad tenía un parque donde iba la juventud escolar femenina los sábados y domingos de cuatro a seis p.m., pues los sábados los varones iban a esas horas a realizar actividades de educación física en el Hipódromo y los domingos no había clases.

1923

En la Exposición (MINISTERIO DE INSTRUCCIÓN PÚBLICA, 1924) correspondiente a 1923 , con un plan trazado desde anterior oportunidad, continua el problema de las becas, lo que afecta la provisión oportuna de docentes para las escuelas alejas de la capital de la República. Las becas las siguen ocupando, en su mayoría, estudiantes de Caracas y zonas cercanas; los estados no han respondido con las cuotas correspondientes de aspirantes y, en oportunidades, las formalidades del concurso hacían perder toda esperanza a quienes tuvieran marcado interés por el magisterio. En relación con ese asunto, señala González Rincones: "El Despacho se ocupa en estudiar las mejoras que puedan introducirse al respecto, tomando en cuenta las dificultades que se han presentado hasta ahora, para obviarlas en cuanto sea posible" (MINISTERIO DE INSTRUCCIÓN PÚBLICA, 1924, p. XV).

Un segundo aspecto es el referido al plan de estudios, ya que hasta la fecha de la cuenta, las actividades de aula en las escuelas normales se han dirigido a la instrucción en las asignaturas que 


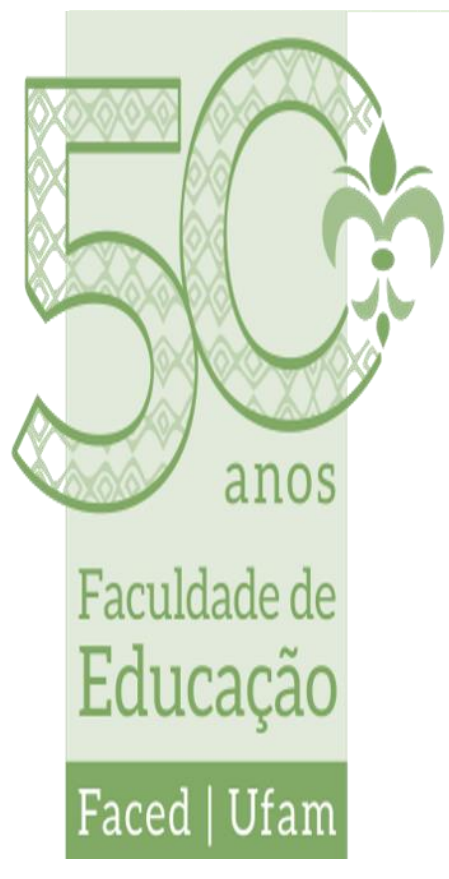

conforman el denominado plan escolástico, definido como aquel que se desarrollaba en las escuelas primarias, descuidando el componente profesional. Para enfrentar parcialmente esta situación, se hicieron cambios tanto en el cuerpo directivo como en el personal docente. Quedaba pendiente la búsqueda de especialistas que tuvieran bajo su responsabilidad las cátedras de carácter pedagógico. Como se apreciará más adelante, la preocupación por los maestros de los maestros, es recurrente. Mientras que la formación del magisterio se mantuviera desarrollando un calco curricular del diseño de las escuelas primarias, el campo pedagógico, propio para el desempeño en el aula, seguiría sin atenderse debidamente,

Otros puntos que destacan en la Exposición de la cuenta, están referidos a diversos temas: a) El otorgamiento de un Certificado Oficial de Suficiencia correspondiente al Título de Maestro de Instrucción Primaria, rendidos los exámenes de rigor; b) La elaboración del Reglamento del Internado de la Escuela Normal Primaria de Hombres, c) La presencia de relaciones internacionales en el ámbito educativo, entre la Escuela № 10 del Séptimo Consejo Escolar de Buenos Aires, denominada Escuela Venezuela, y la Escuela Normal de Mujeres de Caracas; d) Cumplidos los requisitos, se expidió Título Oficial de Maestro de Instrucción Primaria a Pedro Arnal y por informe del Consejo Nacional de Instrucción, se aprobó equivalencia del Título de Preceptor Normalista a César Arreaza, que le había sido conferido en la Escuela Normal de Preceptores "J. A. Núñez", de Santiago de Chile.

Desde el inicio de las escuelas normales en Venezuela, en el siglo XIX, las relaciones de carácter internacional, estuvieron presentes. Bien para contar con docentes extranjeros, especialistas en pedagogía, para estar al frente de instituciones de formación o administrar cátedras especializadas; bien para desarrollo de relaciones interinstitucionales a través del intercambio de experiencias o para enviar aspirantes nacionales a procesos de 
formación. Alemania, Estados Unidos de Norteamérica, Chile, Argentina, fueron parte del circuito de relaciones.

1925

En esta oportunidad, la Exposición (MINISTERIO DE INSTRUCCIÓN PÚBLICA, 1926) del Ministro Rubén González, no tiene el halo esperanzador de oportunidades anteriores: se mantuvo el Curso Normal de tres años y no cuatro como se pensaba en otro tiempo, la vocación para el magisterio se mantiene sin grandes frutos, la selección de aspirantes que se había dado como responsabilidad a los presidentes de los estados, no dio resultados positivos y en el año de la cuenta, apenas cinco estudiantes de la Escuela Normal de Hombres y trece de la Escuela Normal de Mujeres, obtuvieron títulos para el ejercicio del magisterio. Junto a esto, hay que resaltar los siguientes aspectos: se produjo un aumento significativo en el número de internos e internas normalistas, se incrementó el monto de las pensiones del Internado de la Escuela Normal de Hombres y del extranjero se invitaron profesores especialistas para la responsabilidad académica de los cursos identificados como pedagógicos. Con apenas dieciocho docentes graduados en las dos escuelas normales existentes, era muy poco lo que pudiera esperarse para cubrir las vacantes pedagógicas de todo un país. Las decisiones para promover el ingreso de aspirantes para el desempeño docente, habían fracasado rotundamente. Muestra de ello, en parte, con todo lo ventajoso que pareciera ser, se continuaba invitando especialistas extranjeros para cubrir los cursos pedagógicos.

1926

La Instrucción Normalista, al menos en la parte correspondiente a la Exposición de la Memoria, (MINISTERIO DE INSTRUCCIÓN PÚBLICA, 1927) el Ministro Rubén González, apenas si indica algunos aspectos, entre otros: "La instrucción 


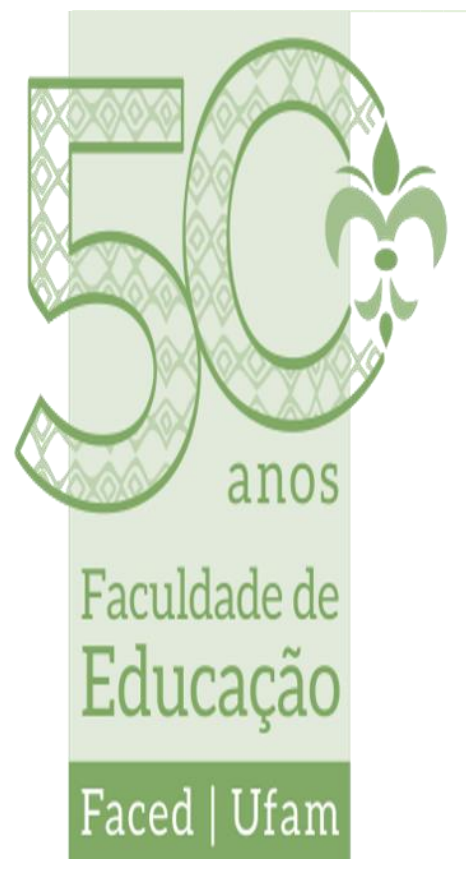

normalista ha continuado su marcha evolutiva hasta donde lo han permitido los medios de que se dispone. Sin embargo, es de notarse cierto incremento en lo que a alumnos se refiere, debido a las constantes gestiones del Ministerio para lograr, con una discreta selección, conseguir en el interior del país alumnos internos que después de graduarse regresen a sus respectivas localidades para servir en los planteles oficiales" (p. XV)

1927

En la Exposición de la Memoria correspondiente al año 1927, el Ministro Rubén González, ante la Cámara Legislativa, no repara en gruesas alabanzas para Juan Vicente Gómez, su gobierno y la política educativa. En acuerdo con la gramática de funcionario público adulador, dice que: vencidas las resistencias, superando vicios, dejando a un lado las deficiencias de antiguas legislaciones, enfrentando acciones entorpecedoras, convencidos los reacios y desaparecida toda oposición, "el plan de instrucción pública... concurren... en la grande empresa de la Rehabilitación Nacional, concebida y llevada a cabo por el Benemérito General Juan Vicente Gómez" (MINISTERIO DE INSTRUCCIÓN PÚBLICA, 1928, p. 321), a quien señala el Ministro González, como estadista de amplia visión patriótica, con vasto alcance de su pupila vigilante, verdadero y grande organizador de pueblos, de mirada clarividente.

Finaliza con los siguientes elogios: "Lo cardinal de la institución, la cultura de las masas populares, la instrucción pública gratuita, eficaz y obligatoria, la escuela primaria, que antes no era sino un plan pedagógico y a la vez patriótico a base de una organización moderna, es obra y gloria exclusiva del General Gómez, como lo son igualmente la fundación de las Escuelas Normales y el impulso progresista que han recibido todas las demás ramas de la enseñanza pública, hoy a la altura de los más adelantados países". (MINISTERIO DE INSTRUCCIÓN PÚBLICA, 1928 , p. V). El despliegue discursivo, incluyendo la mirada 


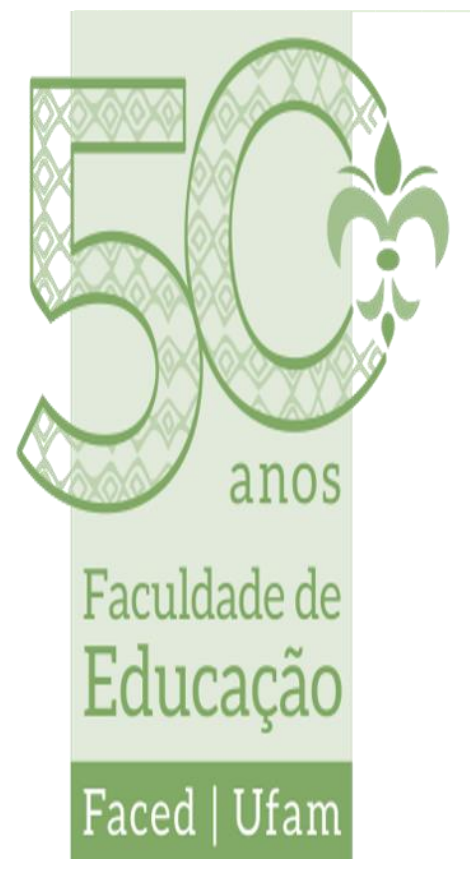

clarividente y el impulso progresista, apenas se había alcanzado para contar exclusivamente con apenas dos escuelas normales.

1928

En esta oportunidad, la parte de la Exposición del Ministro González (HERES, 1981), referida a la Instrucción Normalista, está dedicada, por decirlo de otra manera, al magisterio del magisterio, a quienes tienen responsabilidades de formación en el magisterio. Así lo explica González:

Al utilizar los servicios de los maestros recién graduados, se viene observando cierta deficiencia en la práctica magistral, lo que dejaba ver una preparación experimental poca satisfactoria, a pesar de integrar la ley de suficiencia que es de exigirse al plan científico, pedagógico y práctico necesario para obtener con su aplicación cabal, no maestros en periodos de formación, sino institutores en capacidad de prestar servicios como buenos profesionales, familiarizados con el arte de transmitir, pues de lo contrario se constituirían las escuelas del país en campos de experimentación, donde por falta de dirección técnica, lo mismo pueden adquirirse buenos que malos hábitos, y quedaría sin objeto la existencia de las Escuelas Normales". (FERNÁNDEZ HERES, 1981, p. 1202).

Intentando estrategias para atender tal problemática considerada grave por parte del Ministerio, se aprobó una resolución dirigida a establecer el número de horas/clases que debían ofrecerse para cada asignatura y las correspondientes a las prácticas pedagógicas de los alumnos maestros.

Un nuevo Ministro de Instrucción Pública, Samuel Niño, en su Exposición del año de la cuenta (MINISTERIO DE INSTRUCCIÓN PÚBLICA, 1930), no hace otra cosa que señalar las deficiencias que en la Instrucción Normalista ya indicaba su antecesor. Niño destaca en principio, la importancia de las Escuelas Normales en la estabilidad y organización del magisterio nacional; en esa dirección, vale destacar "la dotación de las Escuelas Normales Primarias, 


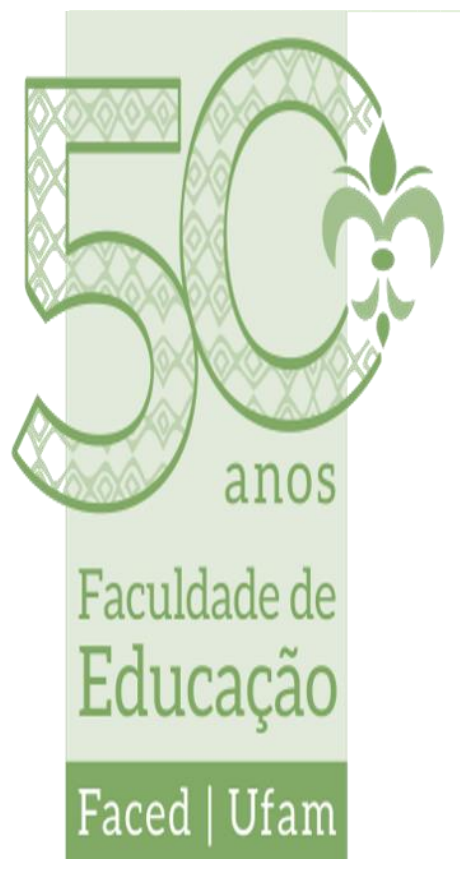

conforme a un plan pedagógico científico" ( $p$. xxiii), pues existiría el peligro de crear un ilimitado número de escuelas primarias, dirigidas "por personas de escasa preparación en el magisterio". (p. XXIII)

En función al requerimiento de organización, el Ministro expone la necesidad de contratar profesores extranjeros, tanto para que se encargaran de las cátedras como de la dirección de las dos escuelas normales existentes. Promoviendo la organización propuesta y triplicando el número de becas en los internados de las normales, "podría asegurarse un regular contingente de maestros graduados en cada año" (p. XXIII). A pocos años de culminar, en sentido estricto, el periodo de gobierno de Juan Vicente Gómez, ciertas dificultades en la gestión de las escuelas normales, se convierten en cíclicas, dado lo no acertado, entre otros aspectos, de las políticas desarrolladas. La contratación de especialistas extranjeros, ante la ausencia de profesionales venezolanos para cubrir vacantes pedagógicas y administrativas de primer orden y el incremento significativo de becas nacionales para estudios magisteriales, esperando el efecto automático de contar con más docentes, eran parte de tales políticas. Es muy probable que las condiciones de carácter social y económico no constituyeran atractivos generales para ser maestra o maestra durante la época en referencia.

1931

Rafael González Rincones, Ministro de Instrucción Pública para el año de la cuenta, en la parte de la Exposición (MINISTERIO DE INSTRUCCIÓN PÚBLICA, 1932) dedicada a la Instrucción Normalista, privilegia tres ámbitos de gestión: la organización del personal docente, el incremento de veintisiete becas en cada una de las escuelas normales y dotación de locales. El aumento del número de becas es considerado "un paso de incalculable valor en el programa de mejoramiento del Despacho" (p. LIII), pues de esa manera, en lapsos de tres años que dura el Curso Normal, será 
posible disponer una generación de relevo magisterial de ciento cuarenta profesionales docentes.

En cuanto a las instalaciones de las escuelas normales, el Presidente Gómez resolvió "ceder para uso de la Instrucción el edificio que, con el objeto de dedicarlo a la Cárcel Modelo, se había construido en el Cerro del Obispo" (p. LIV). El Ministerio de Obras Públicas sería el encargado de las modificaciones y arreglos necesarios. Allí funcionaría el Internado de la Normal de Varones y la Primaria Completa de seis grados.

El edificio donde estaría la Escuela Normal de Mujeres, es un Faced | Ufam edificio de la Nación, en El Paraíso, donde tenía su sede la Escuela Normal de Varones. El Ministerio de Obras Públicas, con "la más entusiasta cooperación del Benemérito General Gómez" (p. LIV), tomaría responsabilidades por el pintado, arreglo de pisos y techos, construcción de galería, cambio de sanitario, entre otras refacciones.

1932

González Rincones acude al optimismo como una estrategia para caracterizar la gestión en el ámbito de la Instrucción Normalista: entusiasmo entre profesores y alumnos, tendencia de renovación, sentido elevado de la misión de las escuelas normales, regularidad en las actividades, multiplicación de factores de rendimiento, arraigo de la misión que al magisterio le ha confiado el Estado y significación cualitativa con el cual se distingue a las escuelas normales.

Algunos aspectos de gestión permiten mostrar: ampliación en la Escuela Normal de Mujeres para abrir dos cursos de la Escuela Primaria anexa, desinfección con azufre en los internados de la Escuela Normal de Mujeres y de la Escuela Normal de Varones, otras medidas profilácticas para evitar la propagación de epidemias y como regalo de aguinaldo del Benemérito Jefe General Juan Vicente Gómez, la entrega de uniformes a las alumnas internas de la Escuela Normal de Mujeres.

Siendo que para la fecha de la Cuenta se había incrementado de cuarenta y tres a setenta el estudiantado interno en cada una de 


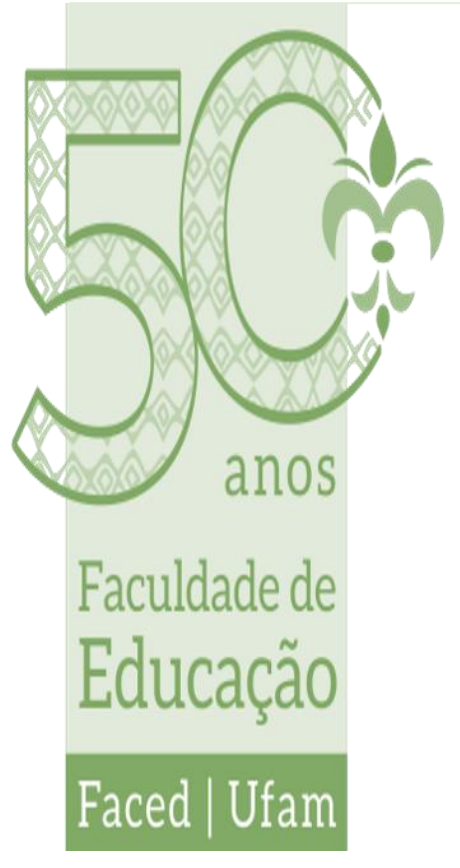

las escuelas normales, hubo que ampliar el radio de acción para la práctica normalista, resultando seleccionadas las escuelas primarias graduadas "Zamora", "San Martín" y la de un maestro No 81, para práctica de varones; y las primarias graduadas "Fermín Toro", "Simón Rodríguez" y la de un maestro № 41, para las hembras.

\section{3}

En año de 1933 es bastante significativo para la historia de la formación docente en Venezuela, pues se crean dos escuelas normales particulares, una en la ciudad de Mérida y otra en Maracaibo. Con esta aprobación no se hace más que darle legitimidad a la iniciativa privada en el campo de la formación académica normalista, "siempre que, como en los casos presentes, la organización y demás condiciones que reúnan los institutos particulares garanticen la eficiencia de tales estudios, requisito indispensable para que el Estado reconozca como pública aquella enseñanza y los alumnos puedan adquirir los certificados oficiales específicos" (MINISTERIO DE INSTRUCCIÓN PÚBLICA, 1933, p. $X L I I)$. Este hecho define tres aspectos muy importantes: el primero, el incremento de dos a cuatro las escuelas normales en el país, ambas ciudades del occidente del país; el segundo, se da espacio a la iniciativa privada para la creación de instituciones de formación magisterial, conservando el Estado el control y la fiscalización y, el tercero, se abren las posibilidades para que en al menos dos ciudades y sus áreas de influencia se pudiera contar en el futuro con escuelas primarias y sus respectivos maestros.

\section{4}

Desde las referencias de los informes elaborados por los Inspectores Técnicos y los enviados por los directores de colegios federales y particulares públicos, se hace evidente un problema sustantivo: la ausencia de docentes titulares en la mayoría del país, por lo cual se ha tenido que acudir a "elementos de mejor 


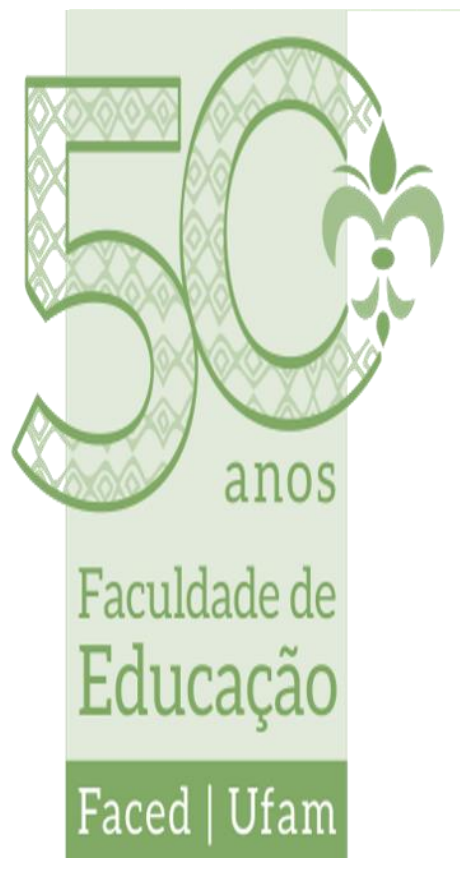

preparación y significación”. El Ministro González Rincones, en esa perspectiva, expresa que "los maestros han de penetrarse de la honradez que requiere su delicada misión, pues aquellos que por su negligencia se abandonan, no sirven como es debido, y al retardar la evolución del niño, hacen traición a las más caras esperanzas del país" (EN FERNÁNDEZ HERES, 1981, v. 2, p. 1517). Luego, en párrafo siguiente, señala:

Da tristeza ver como la indolencia de algunos malos maestros, en medio del gran incremento de alumnos, deja perecer entre sus manos la sagrada custodia de herencias y promesas que se les confió, representada en cada futuro ciudadano; por lo que no les es dable desconocer que la patria será el conjunto de los aportes materiales, morales y científicos de cada uno de ellos". (EN FERNÁNDEZ HERES, 1981, v. 2, p. 1517)

Aun cuando no pudiera generalizarse, la fractura de los criterios de responsabilidad, por abandono de cargo, comprometía seriamente la formación de los futuros ciudadanos. ¿Estaban debilitados o ausentes los espíritus pedagógicos?

\section{5}

Es el último año del régimen gomecista, del tiempo de la Rehabilitación Nacional, del Benemérito y su séquito, le corresponderá a Rómulo Gallegos, Ministro de Instrucción Pública del nuevo gobierno, bajo el General Eleazar López Contreras, presentar la Memoria correspondiente del año de la Cuenta. En su Exposición tiene un aparte subtitulado Escuelas Normales, que bien merece ser citada a título de balance de una época y de las perspectivas para el magisterio normalista venezolano:

Alguien ha llamado donosamente a estos Institutos, Escuelas Anormales. Tales son las condiciones de su funcionamiento. Empezando por el local, que no lo tienen; pasando luego al capítulo de material de enseñanza, deficiente como en todos nuestros institutos; con profesores nombrados muchas veces al acaso, que no reúnen las condiciones necesarias para ser maestros de maestros, no es posible que estos establecimientos respondan a lo que de ellos 


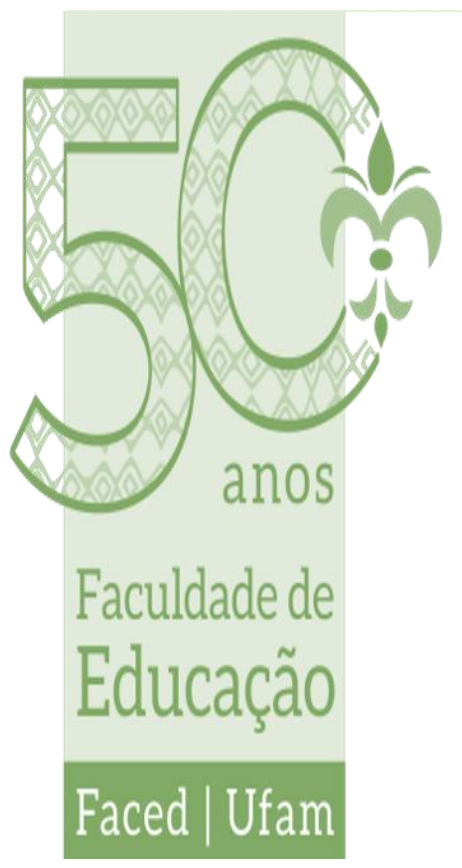

espera la sociedad. El Despacho está seriamente preocupado por la ineficacia de estos institutos y estudia un proyecto de reorganización de esta importante rama de la educación. (CONGRESO DE LA REPÚBLICA, 1985, p. 79).

Por allí se iniciaría otra historia de la formación del magisterio venezolano. Para fin de septiembre de 1936, Eleazar López Contreras, Presidente de la República a la muerte de Gómez creó la Escuela Normal Superior, que llevaría el nombre de Instituto Pedagógico Nacional, para luego convertirse en el Instituto Pedagógico de Caracas. Se encargaría la ENS de la formación para el magisterio de la enseñanza secundaria y normalista; de cooperar en el perfeccionamiento de los docentes en ejercicio e impulsar los estudios científicos sobre educación, pedagogía y orientación vocacional.

\section{PALABRAS FINALES}

En el marco del desarrollo de las escuelas normales durante el tiempo de Juan Vicente Gómez, parte de los conceptos, procesos y modelos que constituyen el pensamiento pedagógico expresado en las Memorias del Ministerio de Instrucción Pública, están representados por un diseño curricular de influencia europea, que mantenía unidades curriculares como francés, música e historia de la educación, luego desaparecidas en el tiempo; la presencia del internado para la escuela primaria en las escuelas normales, para despertar una especie de vocación magisterial temprana; las escuelas de aplicación, como el escenario para el desarrollo del desempeño pedagógico a través de la práctica recurrente; los concursos como norma para aspirar el ingreso en las instituciones de formación primaria; la formación del magisterio vinculada a criterios de responsabilidad, al futuro del país y al desarrollo cultural; la idea persistente de la vocación magisterial; la necesidad de mantener las relaciones interinstitucionales de carácter internacional, tanto en la formación de maestros como en el intercambio de experiencias; la integración de lo pedagógico con lo patriótico; la 
necesidad de formar el magisterio para el magisterio, dando importancia y reconocimiento a la experiencia; el énfasis en las prácticas pedagógicas de los alumnos maestros; y, entre otros referentes, la defensa del Estado docente, que hacía posible reconocer la enseñanza como pública, disponer el control en las instituciones, y otorgar certificados oficiales.

Desde las peculiaridades expuestas en los discursos que Faculdade de recorren el tiempo de las escuelas normales en Venezuela, durante el gobierno de Juan Vicente Gómez, también se plantea para el momento actual, un tema fundamental referido al significado de ser maestro y maestra en estos tiempos, que no es equivalente, por cierto, a ser profesional de la docencia. Como dato histórico, ese debate estuvo en los comienzos del siglo XX y sigue vigente en el $\mathrm{XXI}$. Avanzar en una manera distinta de ser maestra o maestro, es posible que mueva, por lo menos, a dos acontecimientos: el primero, a gestionar una especie de grupo de investigación nacional e internacional, que haga posible compartir otras vertientes para conjugar un pensamiento sobre la formación de maestras y maestras, realmente distinto; el segundo, referido a que el acto de revisitar la historia de las escuelas normales y de todas las instituciones para formación de maestras y maestros, implica también pensar tal formación para nuestro tiempo.

Desde esta perspectiva, los referentes fundamentales de exposición, dejan compromisos esenciales para nuestro tiempo: en primer lugar, la necesidad imperiosa de concebir nuestro propia y auténtica formación para maestras y maestros; en segundo lugar, hay atender críticamente los contenidos históricos del pensamiento referido a la formación de maestras y maestros en Venezuela y en América Latina y el Caribe; en tercer lugar, hay que hacer esfuerzos constantes que permitan compartir una agenda para el debate del pensamiento para la formación de maestras y maestros en nuestros espacios de vida académica, política y social y, en cuarto lugar, identificar, en la búsqueda de un nuevo pensamiento para la formación de maestras y maestros, quienes son aliadas y aliados 


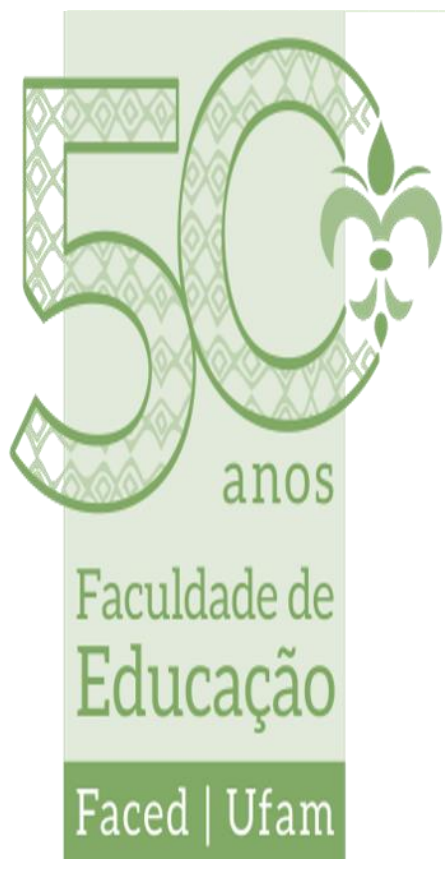

principales en un pro-yecto histórico, político y pedagógico de alcance continental.

\section{REFERENCIAS}

ABREU SUÁREZ, Alirio. Una mirada a las políticas educativas del Estado venezolano desde el llustre americano (1870) al Benemérito (1935). Perspectivas. Revista de historia, geografía, arte y cultura (Año 2 No. 3 ene-jun 2014). Maracaibo: Universidad Nacional Experimental Rafael María Baralt, 2014. Disponible en: http://biblioteca.clacso.edu.ar/Venezuela/ceshc-

unermb/20170219012014/RPS73.pdf. Día de acceso: 7 de mayo. de 2020.

CONGRESO DE LA REPÚBLICA. El pensamiento político venezolano del siglo XX: documentos para su estudio. Gobierno y época del Presidente Eleazar López Contreras. V. 18. Caracas: Congreso de la República, 1986.

FERNÁNDEZ HERES, Rafael. Memoria de cien años. La educación venezolana 1830-1980. Volumen 2. Caracas: Ministerio de Educación, 1981.

FERNÁNDEZ HERES, Rafael. La obra pedagógica de Guillermo Todd: informes sobre el estado de la educación y propuestas para su reforma. Caracas: Academia Nacional de la Historia, 2015.

GÓMEZ, Juan Vicente. Conjuración contra la vida del General Juan Vicente Gómez, presidente de Venezuela y sus consecuencias. Caracas: Imprenta Nacional, 1999. Disponible en: https://archive.org/details/conjuracioncontr00vene/page/n5/mode/2up . Día de acceso: 11 de mayo. de 2020.

GOVEA DE CARPIO, Duilia. Educación Popular y Formación Docente de la Independencia al 23 de Enero de 1959. Caracas: Academia Nacional de la Historia, 1990.

LUQUE, Guillermo. Gomecismo y educación: reforma, contrarreforma y nuevas reformas. 1900-1930, en Investigación y Postgrado, 16(2), 103-133, 2001. Recuperado en 14 de mayo de 2020, dehttp://ve.scielo.org/scielo.php?script=sci arttext\&pid=S131600872001000200006\&lng=es\&tlng=es. Día de acceso: 9 de mayo. de 2020.

LUQUE, Guillermo. (Edit.). Biblioteca Pedagógica Simón Rodríguez. Caracas: Ministerio del Poder Popular para la Cultura, 2008. 


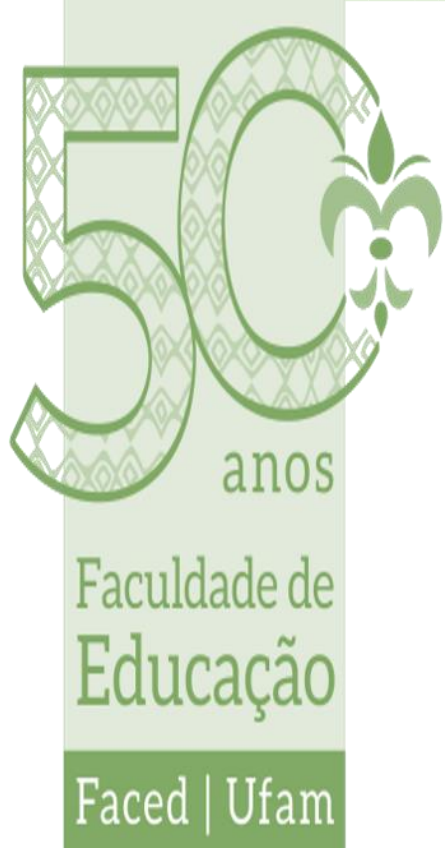

MARTÍNEZ VÁSQUEZ, Emma. La educación de las mujeres en Venezuela. Caracas: Universidad Central de Venezuela, 2005.

MINISTERIO DE INSTRUCCIÓN PÚBLICA. Memoria que presenta el Ministro de Instrucción Pública al Congreso de los Estados Unidos de Venezuela. Caracas: Ministerio de Instrucción Pública, 1917.

MINISTERIO DE INSTRUCCIÓN PÚBLICA. Memoria que presenta el Ministro de Instrucción Pública al Congreso de los Estados Unidos de Venezuela. Caracas: Ministerio de Instrucción Pública, 1918.

MINISTERIO DE INSTRUCCIÓN PÚBLICA. Memoria y cuenta que el Ministro de Instrucción Pública presenta al Congreso Nacional de la República de Venezuela. Volumen 1. Tomo Primero. Caracas: Ministerio de Instrucción Pública, 1919.

MINISTERIO DE INSTRUCCIÓN PÚBLICA. Memoria y cuenta que el Ministro de Instrucción Pública presenta al Congreso Nacional de la República de Venezuela. Caracas: Ministerio de Instrucción Pública, 1924.

MINISTERIO DE INSTRUCCIÓN PÚBLICA. Memoria y cuenta que el Ministro de Instrucción Pública presenta al Congreso Nacional de la República de Venezuela. Caracas: Ministerio de Instrucción Pública, 1926.

MINISTERIO DE INSTRUCCIÓN PÚBLICA. Memoria y que el Ministro de Instrucción Pública al Congreso Nacional de la República de Venezuela. Caracas: Ministerio de Instrucción Pública, 1927.

MINISTERIO DE INSTRUCCIÓN PÚBLICA. Memoria y que el Ministro de Instrucción Pública presenta al Congreso Nacional de la República de Venezuela. Caracas: Ministerio de Instrucción Pública, 1928.

MINISTERIO DE INSTRUCCIÓN PÚBLICA. Memoria y cuenta que el Ministro de Instrucción Pública presenta al Congreso Nacional de la República de Venezuela. Caracas: Ministerio de Instrucción Pública, 1929.

MINISTERIO DE INSTRUCCIÓN PÚBLICA. Memoria y cuenta que el Ministro de Instrucción Pública presenta al Congreso Nacional de la República de Venezuela. Caracas: Ministerio de Instrucción Pública, 1930.

MINISTERIO DE INSTRUCCIÓN PÚBLICA. Memoria y cuenta que el Ministro de Instrucción Pública presenta al Congreso 


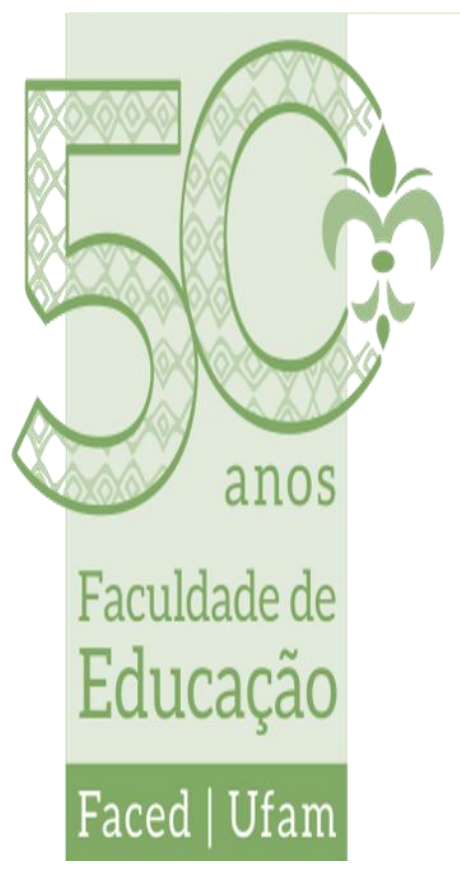

Nacional de la República de Venezuela. Caracas: Ministerio de Instrucción Pública, 1932.

MINISTERIO DE INSTRUCCIÓN PÚBLICA. Memoria y cuenta que el Ministro de Instrucción Pública presenta al Congreso Nacional de la República de Venezuela. Caracas: Ministerio de Instrucción Pública, 1933.

MINISTERIO DE INSTRUCCIÓN PÚBLICA. Memoria y cuenta que el Ministro de Instrucción Pública presenta al Congreso Nacional de la República de Venezuela. Caracas: Ministerio de Instrucción Pública, 1934.

MINISTERIO DE INSTRUCCIÓN PÚBLICA. Memoria y cuenta que el Ministro de Instrucción Pública presenta al Congreso Nacional de la República de Venezuela. Caracas: Ministerio de Instrucción Pública, 1935.

MINISTERIO DE INSTRUCCIÓN PÚBLICA. Memoria y cuenta que el Ministro de Instrucción Pública presenta al Congreso Nacional de la República de Venezuela. Caracas: Ministerio de Instrucción Pública, 1936.

OLIVAR, José Alberto. Las reformas educativas de Felipe Guevara Rojas (1914-1916). Educab, [S.I.], n. 6, p. 37-60, sep. 2015. ISSN 1856-9587. Disponible en: http://revistasenlinea.saber.ucab.edu.ve/temas/index.php/educab/arti cle/view/2562. Día de acceso: 14 mayo 2020.

PINTO IGLESIAS, Teodoro y GARCÍA, Blanquita C. La formación de formadores en Venezuela: la formación de maestros (1830-1935) Laurus, vol. 8, núm. 14, 2002, pp. 36-60. Disponible en: https://www.redalyc.org/articulo.oa?id=76111334004. Día de acceso: 11 de mayo. de 2020.

VARGAS PONCE, José. Las escuelas normales y la formación docente en Venezuela, 1900-1935, 2020 Disponible en: https://josevargasponce.wordpress.com/2020/03/02/las-escuelasnormales-y-la-formacion-docente-en-venezuela-1900-1935/. Día de acceso: 10 de mayo. de 2020.

PORTILLO, Gustavo y BUSTAMANTE, Sonia. Educación y legitimidad, 1870-1990. Caracas: Universidad Central de Venezuela, 19 